\title{
An Insight into the Role of Various Factors Involved in the Pathogenesis of Dry Eyes after Manual Small-incision Cataract Surgery: A Mini Review
}

\author{
Mamleshwari Patil $^{1}$, Venkatesh Sugantharaj ${ }^{2}$, Shruti P Hegde $^{3}$
}

\begin{abstract}
Background: A significant proportion of the patients develop symptoms of dry eyes following manual small-incision cataract surgery (MSICS). The pathogenesis of this complication remains unclear. Various studies have been done to study this and multiple mechanisms have been proposed. The idea of this review is to give a comprehensive insight to the factors involved in the pathogenesis of dry eyes after MSICS. An extensive electronic literature search was done using search engines such as PubMed and Google Scholar using the mesh terms/key words "Pathogenesis, postoperative dry eyes, manual small incision cataract surgery". A total of 26 studies were included in the review. The various etiological factors were discussed in detail. The most common factors were noted.

Conclusion: There are myriad factors involved in the occurrence of postoperative dry eye of which transection of corneal nerves during surgery and the use of postoperative topical medication with preservatives rank as the two most important causes.

Keywords: Etiopathogenesis, Manual small-incision cataract surgery, Mechanisms, Post-operative dry eyes.

Annals of SBV (2019): 10.5005/jp-journals-10085-8107
\end{abstract}

\section{INTRODUCTION}

The most common cause of preventable and reversible blindness in the world is a cataract in elderly patients. All patients diagnosed with cataracts will be requiring surgical interventions eventually in order to achieve restoration of vision and visual rehabilitation. At present different types of cataract surgeries are being performed; among those manual small incision cataract surgery (MSICS) has emerged as a preferred technique in the management of cataracts, especially in a rural setup and in cases of grade III-IV nuclear cataracts. ${ }^{1,2}$ This surgery is performed through a $6.0-6.5 \mathrm{~mm}$ selfsealing sclerocorneal tunnel incision either in the superior or in the temporal portions of the sclera. ${ }^{3}$ The incision is mostly left unsutured in the event of a good apposition of the sclerocorneal tunnel. In the immediate postoperative period, a significant proportion of the patients develop symptoms of dry eyes, which vary from mild ocular discomfort, irritation, dryness, burning sensation to redness of eyes, watering from eyes and even ocular pain. This condition may also cause serious irritation of interpalpebral surface, particularly cornea. Severe dry eye can affect the patient's vision, ocular and general health, and quality of life.

According to the Dry Eye Workshop (DEWS) held in 2007, dry eye is "A multifactorial disease of the tears and ocular surface that results in symptoms of discomfort, visual disturbance and tear film instability."4 The mechanism of development of dry eyes involves any disease or dysfunction of the lacrimal functional unit (LFU) that consists of the ocular surface (meibomian glands, conjunctiva, and cornea), lacrimal glands, eyelids, and the sensory and motor nerves connecting them. All these form a functional unit to maintain production and clearance of tears; and any disturbance in this unit can result in the poorly maintained and unstable tear film that causes dry eye disease. ${ }^{5,6}$ Although age may be a factor, the etiology of dry eye disease following MSICS is multifactorial. ${ }^{7}$ The proposed factors that can lead to dry eyes following cataract $\overline{{ }^{1-3} \text { Department of Ophthalmology, Shri Sathya Sai Medical College and }}$ Research Institute, Chennai, Tamil Nadu, India

Corresponding Author: Venkatesh Sugantharaj, Department of Ophthalmology, Shri Sathya Sai Medical College and Research Institute, Chennai, Tamil Nadu, India, Phone: +91 9840062591, e-mail: venkatophthal@gmail.com

How to cite this article: Patil M, Sugantharaj V, Hegde SP. An Insight into the Role of Various Factors Involved in the Pathogenesis of Dry Eyes after Manual Small-incision Cataract Surgery: A Mini Review. Ann SBV 2019;8(2):51-53.

Source of support: Nil

Conflict of interest: None

surgery are cutting of nerve endings due to surgical incision, long-term use of topical medications, presence of preservatives in eye drops, decrease in goblet cell density following cataract surgery, surgical trauma and trauma due to inflammation of the ocular surface, meibomian gland dysfunction, and prolonged use of operating microscope light. In this review, we have attempted to provide an insight into the various etiological factors of the dry eyes occurring after cataract surgery.

We have done an extensive electronic literature search by means of search engines like PubMed and Google scholar using the mesh terms/key words "Pathogenesis, etiopathogenesis, mechanisms, postoperative dry eyes, manual small-incision cataract surgery". The database revealed 77 articles of which 26 articles were found relevant to our study and have incorporated them.

Multiple factors are responsible for the pathogenesis of dry eyes after MSICS. The role of various factors that may be involved in this can be understood by knowing the possible mechanisms suggested by various authors and are summarized in Table 1.

(c) The Author(s). 2019 Open Access This article is distributed under the terms of the Creative Commons Attribution 4.0 International License (https://creativecommons. org/licenses/by-nc/4.0/), which permits unrestricted use, distribution, and non-commercial reproduction in any medium, provided you give appropriate credit to the original author(s) and the source, provide a link to the Creative Commons license, and indicate if changes were made. The Creative Commons Public Domain Dedication waiver (http://creativecommons.org/publicdomain/zero/1.0/) applies to the data made available in this article, unless otherwise stated. 
Table 1: Author details and pathogenic factors involved

\begin{tabular}{|c|c|c|}
\hline S. no & Author details & Mechanism/pathogenic factors \\
\hline 1 & $\begin{array}{l}\text { Ishrat et al., Sutu et al., } \\
\text { Venugopal et al. }\end{array}$ & $\begin{array}{l}\text { Cutting of nerve endings due to } \\
\text { surgical incision }\end{array}$ \\
\hline 2 & $\begin{array}{l}\text { Baveja et al., Jayshree } \\
\text { et al., Jagannath et al., } \\
\text { Movahedan et al., Park } \\
\text { et al., Sitompul et al. }\end{array}$ & $\begin{array}{l}\text { Tear film instability following } \\
\text { surgery }\end{array}$ \\
\hline 3 & $\begin{array}{l}\text { Lee et al., Congdon } \\
\text { et al. }\end{array}$ & $\begin{array}{l}\text { Long-term use of topical } \\
\text { medication }\end{array}$ \\
\hline 4 & $\begin{array}{l}\text { Kusano et al., Kim et al., } \\
\text { Jee et al. }\end{array}$ & $\begin{array}{l}\text { Presence of preservatives in eye } \\
\text { drops }\end{array}$ \\
\hline 5 & Ganvit et al. & $\begin{array}{l}\text { Decrease goblet cell density } \\
\text { following cataract surgery }\end{array}$ \\
\hline 6 & Sutu et al. & $\begin{array}{l}\text { Surgical trauma and trauma due } \\
\text { to inflammation of the ocular } \\
\text { surface }\end{array}$ \\
\hline 7 & Bron et al. & Meibomian gland dysfunction \\
\hline 8 & Ipek et al. & Operating microscope light \\
\hline
\end{tabular}

\section{Discussion}

One of the main mechanisms discussed as a contributory factor in the development of dry eye disease following cataract surgery, in studies done by Ishrat et al., Sutu et al., and Venugopal et al. was cutting of the corneal nerves due to surgical incision. ${ }^{8-10}$ The cornea has a rich nerve supply which is vital for its structural and functional integrity. The entry into the anterior chamber made during the small-incision cataract surgery causes direct cutting of these nerve fibers, thereby causing a reduced corneal sensation. This further disturbs the LFU feedback which in turn causes a reduction in the flow of tears and blink rate. This will lead to tear film instability. Neurogenic inflammation also might be one of the causes for reduced corneal sensitivity. ${ }^{11}$

Studies performed by Kusano et al., Lee et al., Kato et al., and Congdon et al. have mentioned that prolonged use of topical medications as eye drops postoperatively can cause dry eyes de novo or worsen the clinical features in patients with preexisting dry eyes. ${ }^{12-15}$ Topical steroids and nonsteroidal anti-inflammatory drugs (NSAIDs) were the main culprits in this category.

Most of the commonly used postoperative medications such as corticosteroids, NSAIDs, and antibiotic eye drops have preservatives in them. Preservatives are generally used to make the eye drops more stable by increasing the shelf life of the drug, to keep it sterile, and sometimes to increase the penetrance of the drug. Although there are a variety of preservatives, the most widely used one is benzalkonium chloride. Along with all its desired benefits, it brings the danger of developing dry eye disease due to its toxicity to the ocular surface particularly the corneal epithelium. ${ }^{16}$ It also delays the healing process of the ocular surface. Some postoperative medications like moxifloxacin antibiotic eye drops are available as a preservative-free formula also. ${ }^{17}$

Jee et al. compared the preservative-free and preserved formulae of two drugs sodium hyaluronate $0.1 \%$ and fluorometholone $0.1 \%$ eye drops following cataract surgery and concluded that preservative-free formulae are also effective in controlling symptoms and signs of dry eyes after cataract surgery. ${ }^{18}$

Studies by Baveja et al., Jayshree et al., Movahedan et al., and Lakshmi et al. highlighted the changes in tear film parameters such as tear film breakup time, fluorescein staining of cornea and conjunctiva, and Schirmer-I test and also the subjective symptom scores (ocular surface disease index) before and after the cataract surgery which indicates toward the postoperative dry eyes. These studies emphasize the irregularities of the tear film due to ocular surface damage after MSICS. ${ }^{19-22}$

Sitompul et al. gave an insight on sensitivity change in cornea and changes in the tear film of the ocular surface following cataract surgery. ${ }^{23}$

Meibomian gland dysfunction as a causative factor for postoperative dry eye was also found in the literature., ${ }^{9,24}$ Dryness of eyes after cataract surgery is associated with a reduction in goblet cell density, which is also well-known., ${ }^{911}$ Topical diclofenac use was found to be responsible for the reduction in goblet cells in comparison with the other commonly used topical NSAIDs. ${ }^{14}$

Surgical trauma and trauma due to inflammation to the ocular surface were mentioned as the causative factors in the studies by Sutu et al. and Ganvit et al., respectively.,11 Ganvit et al. conducted a study comprising 100 patients including 47 males and 53 females between the age-group of 45-75 years, for evaluating dry eye changes following cataract surgery. In their study, they focused on the ocular surface damage due to inflammatory mediators and also neurogenic inflammation resulting after MSICS. ${ }^{11}$ This was most often encountered in patients with complicated cataracts and those with pseudoexfoliation. ${ }^{25}$

Intraoperative exposure to the operating microscope light for prolonged time periods was studied and discussed as an important contributory factor for postoperative dry eyes. ${ }^{26}$ This was most often encountered in surgeries by novice manual small-incision surgeons who generally took a long time to complete the surgery.

\section{Conclusion}

Clinically significant dry eye symptomatology was common after MSICS. There are myriad factors involved in its occurrence, of which transection of corneal nerves during surgery, tear film instability, and the use of postoperative topical medication with preservatives rank as the most important causes. A reduction in surgical incision size during MSICS by performing back cuts, using preservative-free topical medications in the postoperative period and shortening the duration of the surgical procedure to limit the microscope light exposure time are some of the recommendations to reduce the incidence of postoperative dry eye symptoms.

\section{References}

1. Gogate $P$, Deshpande M, Nirmalan PK. Why do phacoemulsification Manual small-incision cataract surgery is almost as effective, but less expensive. Ophthalmology 2007;114(5):965-968. DOI: 10.1016/j. ophtha.2006.08.057.

2. Devendra J, Agarwal S, Singh PK. A comparative study of clear corneal phacoemulsification with rigid IOL versus SICS; the preferred surgical technique in low socio-economic group patients of rural areas. J Clin Diagnos Res: JCDR 2014;8(11):VC01. DOI: 10.7860/ JCDR/2014/10717.5208.

3. Jauhari N, Chopra D, Chaurasia RK, Agarwal A. Comparison of surgically induced astigmatism in various incisions in manual small incision cataract surgery. Int J Ophthalmol 2014;7(6):1001. DOI: 10.3980/j.issn.2222-3959.2014.06.16.

4. Lemp MA, Foulks GN. The definition and classification of dry eye disease. Ocul Surf 2007;5(2):75-92. DOI: 10.1016/S1542-0124(12)700812.

5. Kanski JJ, Bowling B. Clinical ophthalmology: a systematic approach. Elsevier Health Sciences 2011. 
6. Stern ME, Gao J, Siemasko KF, Beuerman RW, Pflugfelder SC. The role of the lacrimal functional unit in the pathophysiology of dry eye. Exp Eye Res 2004;78(3):409-416. DOI: 10.1016/j.exer.2003.09.003.

7. Moss SE, Klein R, Klein BE. Incidence of dry eye in an older population. Investig Ophthalmol Vis Sci 2003;44(13):810.

8. Ishrat S, Nema N, Chandravanshi SC. Incidence and pattern of dry eye after cataract surgery. Saudi J Ophthalmol 2019;33(1):34-40. DOI: 10.1016/j.sjopt.2018.10.009.

9. Sutu C, Fukuoka H, Afshari NA. Mechanisms and management of dry eye in cataract surgery patients. Curr Opin Ophthalmol 2016;27(1):2430. DOI: $10.1097 /$ ICU.0000000000000227.

10. Venugopal KC, Krishnaraj PA, Chandan N. Evaluation of dryness of eyes after manual small incision cataract surgery with corneoscleral tunnel incision. J Clin Diagnos Res 2012;6(6).

11. Ganvit SS, Ahir HD, Sadhu J, Pandya NN. Study of dry eye changes after cataract surgery. Int J Res Med 2014;3(2):142-145.

12. Kusano M, Uematsu M, Kumagami T, Sasaki H, Kitaoka T. Evaluation of acute corneal barrier change induced by topically applied preservatives using corneal transepithelial electric resistance in vivo. Cornea 2010;29(1):80-85. DOI: 10.1097/ICO.0b013e3181a3c3e6.

13. Lee JE, Kim NM, Yang JW, Kim SJ, Lee JS, Lee JE. A randomised controlled trial comparing a thermal massager with artificial teardrops for the treatment of dry eye. Br J Ophthalmol 2014;98(1):4651. DOI: 10.1136/bjophthalmol-2013-303742.

14. Kato K, Miyake K, Kondo N, Asano S, Takeda J, Takahashi A, et al. Conjunctival goblet cell density following cataract surgery with diclofenac versus diclofenac and rebamipide: a randomized trial. Am J Ophthalmol 2017;181:26-36. DOI: 10.1016/j.ajo.2017.06.016.

15. Congdon NG, Schein OD, Von Kulajta P, Lubomski LH, Gilbert $D$, Katz J. Corneal complications associated with topical ophthalmic use of nonsteroidal antiinflammatory drugs. J Catar Refract Surg 2001;27(4):622-631. DOI: 10.1016/s0886-3350(01)00801-x.

16. Zhang R, Park M, Richardson A, Tedla N, Pandzic E, de Paiva CS, et al. Dose-dependent benzalkonium chloride toxicity imparts ocular surface epithelial changes with features of dry eye disease. Ocul Surf 2019(1). DOI: 10.1016/j.jtos.2019.11.006.

17. Kim MS, Kim HK, Kim JM, Choi CY. Comparison of contamination rates between preserved and preservative-free fluoroquinolone eyedrops.
Graefe's Arch Clin Experiment Ophthalmol 2013;251(3):817-824. DOI: 10.1007/s00417-012-2152-z.

18. Jee D, Park M, Lee HJ, Kim MS, Kim EC. Comparison of treatment with preservative-free versus preserved sodium hyaluronate $0.1 \%$ and fluorometholone $0.1 \%$ eyedrops after cataract surgery in patients with preexisting dry-eye syndrome. J Catar Refract Surg 2015;41(4):756-763. DOI: 10.1016/j.jcrs.2014.11.034.

19. Baveja A, Batra N. A comparative study of tear film parameters before and after small incision cataract surgery and phacoemulsification. J Evid Based Med 2017;4(26):1510-1513.

20. Jayshree MP, Shivkumar H, Monalisha P, Mallikarjun S. A prospective study of dry eye after manual small incision cataract surgery in rural population of Bagalkot. J Clin Res Ophthalmol 2017;4(2): 25-29.

21. Movahedan A, Djalilian AR. Cataract surgery in the face of ocular surface disease. Curr Opin Ophthalmol 2012;23(1):68-72. DOI: 10.1097/ ICU.0b013e32834d90b7.

22. Lakshmi PS, Sandhya CS, Jagannath C, Madhavi K. Changes in the tear film after manual small incision cataract surgery-a prospective study. Offici Sci J Delhi Ophthalmolog Soc 2018;29(2):26-30. DOI: 10.7869/ djo.392.

23. Sitompul R, Sancoyo GS, Hutauruk JA, Gondhowiardjo TD. Sensitivity change in cornea and tear layer due to incision difference on cataract surgery with either manual small-incision cataract surgery or phacoemulsification. Cornea 2008;27(Suppl 1):S13-S18. DOI: 10.1097/ ICO.0b013e31817f29d8.

24. Foulks GN, Bron AJ. Meibomian gland dysfunction: a clinical scheme for description, diagnosis, classification, and grading. Ocul Surf 2003;1(3):107-126. DOI: 10.1016/s1542-0124(12)70139-8.

25. Hegde SP, Sekharreddy MR, Kumar MR, Dayanidhi VK. Prospective study of hypermature cataract in Kanchipuram district: causes of delayed presentation, risk of lens-induced glaucoma and visual prognosis. Kerala J Ophthalmol 2018;30(3):187. DOI: 10.4103/kjo. kjo_50_18.

26. Ipek T, Hanga MP, Hartwig A, Wolffsohn J, O'Donnell C. Dry eye following cataract surgery: the effect of light exposure using an in-vitro model. Contact Lens Anter Eye 2018;41(1):128-131. DOI: 10.1016/j.clae.2017.11.003. 